SISTEMA
ELETRÔNICO
DE REVISTAS
SER I UfPR

\title{
Avaliação do Zoneamento Ecológico-Econômico Costeiro (ZEEC) como ferramenta de subsídio ao licenciamento ambiental da atividade de extração mineral de areia no litoral norte do Rio Grande do Sul
}

\section{Evaluation of the Coastal Ecological-Economic Zoning (ZEEC) as a tool to subsidize the environmental licensing of the activity of sand mining in the northern coast of Rio Grande do Sul}

\author{
Karen Jurema Ribeiro GUIMARÃES ${ }^{1 *}$, João Luiz NICOLODI ${ }^{1}$ \\ ${ }^{1}$ Universidade Federal do Rio Grande (FURG), Rio Grande, RS, Brasil. \\ *E-mail de contato: kakag20@hotmail.com
}

Artigo recebido em 20 de dezembro de 2017, versão final aceita em 7 de novembro de 2018.

RESUMO: Neste artigo, buscou-se avaliar a utilização do Zoneamento Ecológico-Econômico Costeiro (ZEEC) como ferramenta de subsídio ao licenciamento ambiental das atividades de mineração de areia do litoral norte do Rio Grande do Sul. Para tal, o estudo foi realizado em duas fases: na primeira foram analisados os processos de licenciamento ambiental no que tange à utilização do ZEEC e sua concordância com as diretrizes ambientais do instrumento; na segunda foi analisado o processo de gestão da atividade de extração mineral de areia com base nos procedimentos de adequação da atividade às diretrizes do ZEEC e o resultado do processo de gestão da atividade em si. Foram analisados 35 processos de licenciamento, sendo que o ZEEC não foi citado em 74\% dos documentos de licença, porém 94\% das licenças analisadas estão em conformidade com as diretrizes do instrumento. Após a análise do processo de gestão, observou-se que 49\% das mineradoras participaram da negociação com a Fundação Estadual de Proteção Ambiental (FEPAM), as quais assinaram um Termo de Controle Ambiental (TCA) para a desativação ou adequação das suas atividades. Após o prazo de vigência do TCA foram desativadas nove mineradoras $(52,4 \%)$, seis continuaram em atividade $(35,3 \%)$ e duas $(11,8 \%)$ permaneceram sem definição. Ao final do processo de gestão, seis mineradoras cumpriram efetivamente o TCA enquanto que os processos das demais não apresentam informações conclusivas sobre o cumprimento do termo, ou ainda estavam indisponíveis para consulta ou arquivados sem definição. Por fim, conclui-se que apesar de o ZEEC do litoral norte não ser normatizado e nem ter sua utilização obrigatória, ele cumpriu seu papel como ferramenta de planejamento e gestão, dando suporte a outros instrumentos como o licenciamento ambiental. $\mathrm{O}$ aspecto determinante da pesquisa foi a análise do conflito gerado entre a atividade 
de mineração e as diretrizes do ZEEC, o que vem a confirmar a importância dessa ferramenta no planejamento das atividades da região.

Palavras-chave: Zoneamento Ecológico Econômico (ZEEC); licenciamento ambiental; litoral norte do Rio Grande do Sul; extração mineral de areia.

ABSTRACT: The objective of this article was to evaluate the use of the Coastal Ecological-Economic Zoning (CEEZ) as a tool to subsidize the environmental licensing of the Sand Mining activities of the Northern Coast of Rio Grande do Sul. Therefore, the study was carried out in two phases: the first analyzed the environmental licensing processes regarding the use of CEEZ and its agreement with the environmental guidelines of the instrument. The second analyzed the process of management of the mining activity based on the activity adaptation procedures to the CEEZ guidelines and the result of the management process activity itself. CEEZ was not cited in $74 \%$ of the license documents, however, $94 \%$ of the licenses analyzed are in compliance with the guidelines of the instrument. After analyzing the management process, it was observed that $49 \%$ of the mining companies participated in the negotiations with State Fundation for Environmental Protection (FEPAM), which signed an Environmental Control Term (ECT) for the adequacy or deactivation of its activities. After the term of validity of the TCA, nine $(52,4 \%$ mining companies were deactivated, six $(35,3 \%)$ remained in activity and two $(11,8 \%)$ remained without definition. At the end of the management process, six mining companies effectively complied with the ECT, while the others' processes did not present conclusive information on compliance with the term, or were unavailable for consultation or yet filed without definition. Finally, it is concluded that although the CEEZ of the North Coast is not regulated nor it is of mandatory use, it fulfilled its role as a planning and management tool, supporting other instruments such as environmental licensing. The determinant aspect of the research was the analysis of the conflict generated between the mining activity and the guidelines of the CEEZ, which confirms the importance of this tool in the planning of the region activities.

Keywords: Coastal Ecological-Economic Zoning (CEEZ); environmental licensing; north coast of Rio Grande do Sul; sand mining.

\section{Introdução}

Em função da intensa exploração dos seus recursos naturais e do uso desordenado do solo, as zonas costeiras são áreas frágeis do ponto de vista da gestão. Em nível mundial, as zonas costeiras podem ser consideradas regiões de inúmeros contrastes, onde ocorrem acelerados processos de intensa urbanização, atividade portuária e industrial relevante e a exploração turística em larga escala (Gruber et al., 2003).

A Constituição Federal define a Zona Costeira do Brasil como zona de patrimônio nacional e sua ocupação e o uso dos recursos naturais serão feitos dentro das condições que assegurem a preservação do meio ambiente. É a região onde se encontra aproximadamente $25 \%$ da população brasileira e considerável número de cidades, sobretudo as capitais, apresentando preocupante e crescente nível de expansão urbana desordenada (MMA, 2015).

Moraes (1999) e Portz et al. (2011) afirmam que a ocupação da zona costeira no Brasil vem se intensificando nas últimas décadas, em consequência de três vetores principais de desenvolvimento: a urbanização, a industrialização e a exploração turística. Além desses vetores, os autores destacam 
as migrações intrarregionais, a reestruturação produtiva e as emancipações municipais juntamente à inserção de novos contingentes populacionais, de usos e atividades nos municípios litorâneos.

O Gerenciamento Costeiro Integrado (GCI) é um processo contínuo e dinâmico pelo qual decisões são tomadas visando ao uso sustentável, desenvolvimento e proteção das áreas marinhas e costeiras e de seus recursos (Cicin-Sain \& Knecht, 1998). O GCI surgiu da necessidade de se administrar os recursos naturais da zona costeira de forma sustentável devido ao grande atrativo comercial, industrial e turístico.

A zona costeira brasileira estende-se por mais de $10.800 \mathrm{~km}$, quando considerados os recortes e as reentrâncias naturais da costa, e possui uma área de aproximadamente 514 mil km². Em 1988 foi instituído o Programa Nacional de Gerenciamento Costeiro (Gerco) e o Plano Nacional de Gerenciamento Costeiro (PNGC) visando a responder adequadamente às demandas e problemas relacionados à zona costeira brasileira (Zamboni \& Nicolodi, 2008).

O Gerco é responsável por operacionalizar o PNGC de forma descentralizada e participativa, tendo o Ministério do Meio Ambiente (MMA) como órgão central coordenando todas as ações no nível federal e os órgãos ambientais dos 17 estados litorâneos como executores estaduais, os quais buscam integrar suas ações com os municípios (Asmus et al., 2006).

O estado do Rio Grande do Sul iniciou seu Programa de Gerenciamento Costeiro (Gerco-RS), entre 1988 e 2016, tendo a Fundação Estadual de Proteção Ambiental Henrique Luiz Roessler
(FEPAM) como executora estadual do programa, apresentando seu foco no ordenamento territorial e na recuperação e reabilitação das áreas degradadas ou descaracterizadas.

Dentre os instrumentos de gestão utilizados pelo Gerco-RS destaca-se o Zoneamento Ecológico-Econômico Costeiro do litoral norte do RS (ZEEC-RS), o qual faz parte da primeira edição do Caderno de Planejamento e Gestão Ambiental publicado pela Fepam em 2000, intitulado "Diretrizes Ambientais para o Desenvolvimento dos Municípios do Litoral Norte", integrando o processo de enquadramento dos recursos hídricos do Estado ${ }^{1}$.

A publicação das diretrizes para cada uma das zonas do ZEEC representa os critérios ambientais utilizados pela instituição no seu trabalho habitual de licenciamento ambiental como também são fundamentais na elaboração dos Planos Diretores Municipais e outras políticas ambientais.

Segundo o Decreto Federal 4.297 de 2002, que regulamenta a Política Nacional de Meio Ambiente (PNMA), o ZEE é um instrumento de organização do território a ser seguido obrigatoriamente na implantação de planos, obras e atividades públicas e privadas, podendo estabelecer vedações, restrições, e ainda, se for o caso, determinar inclusive a realocação de atividades incompatíveis com suas diretrizes gerais. Nesse contexto, o ZEE deve ser um instrumento indispensável ao processo de licenciamento ambiental de empreendimentos e atividades que utilizam recursos ambientais, consideradas efetiva ou potencialmente poluidoras de uma região (Medauar, 2015).

Nesse contexto, o zoneamento ecológico-econômico (ZEE), instrumento da Política Nacional do

${ }^{1} \mathrm{O}$ enquadramento de recursos hídricos é um instrumento previsto na Política Nacional de Recursos Hídricos (Lei 9433/1997). 
Meio Ambiente (PNMA), tem sido implementado pelo poder público em diversas escalas de trabalho e em frações do território nacional. Municípios, estados da federação e órgãos federais têm executado ZEEs e avançado na conexão entre os produtos gerados e outros instrumentos de políticas públicas, com o objetivo de efetivar ações de gestão ambiental e territorial integradas.

O zoneamento é também considerado no Plano Nacional de Gerenciamento Costeiro, instituído pela Lei 7.661/81, que no Art. $3^{\circ}$ indica que o mesmo deverá ser previsto para usos e atividades da zona costeira, priorizando a conservação e proteção dos recursos naturais, renováveis e não renováveis. A regulamentação, por meio do Decreto 5.300/2004, indica que cabe ao ZEEC - Zoneamento Ecológico Econômico Costeiro - orientar o processo de ordenamento territorial da costa, garantindo as condições para o desenvolvimento sustentável dessa porção do território, mediante o apoio às ações de monitoramento, licenciamento ambiental e elaboração de instrumentos econômicos para a gestão ambiental, dentre outras.

O Zoneamento continental (aquele previsto na PNMA) e o Zoneamento costeiro têm trilhado caminhos distintos, contando-se com zoneamentos elaborados em diferentes feições e escalas, carecendo, no entanto, de uma visão mais integrada do território, que considere, inclusive, o ambiente marítimo como parte integrante do território nacional (Nicolodi et al. 2018).

O Decreto Federal 5300/2004, que regulamenta a Lei $n^{\circ} 7.661$, de 16 de maio de 1988, define o Zoneamento Ecológico-Econômico Costeiro (ZEEC) como um instrumento que orienta o processo de ordenamento territorial, fundamental para a obtenção das condições de sustentabilidade do de- senvolvimento da zona costeira, em concordância com as diretrizes do ZEE do território nacional, servindo como mecanismo de apoio às ações de monitoramento, licenciamento, fiscalização e gestão (Brasil, 2004).

Becker \& Egler (1996) definem ZEE como "um instrumento político e técnico do planejamento cuja finalidade última é otimizar o uso do espaço e as políticas públicas". Segundo os autores, essa otimização é alcançada pelas inúmeras vantagens que esse instrumento oferece, como: informações sobre o território, necessárias para planejar a sua ocupação racional, e o uso sustentável dos recursos naturais, pois provê uma informação integrada em uma base geográfica e classifica o território segundo suas potencialidade e vulnerabilidade.

Ainda que algumas análises sobre o ZEE e o ZEEC tenham sido propostas por diversos autores no país (Ab'Saber, 1989; Schubart, 2000; Ranieri, 2000; Leite, 2001; Oliveira, 2004; Lima, 2006; Montaño et al., 2007; Gandra, 2008; Santos, 2010; Bastos \& Silva, 2010; Ferreira, 2011; Araújo et al. 2011; Vasconcelos et al. 2013; Ogata, 2015), ainda restam dúvidas quanto ao resultado do ZEEC como efetivo instrumento de planejamento da zona costeira: se ele está integrado a outros instrumentos de planejamento e ordenamento territorial e se está servindo de subsídio a outros instrumentos de gestão ambiental ao qual é proposto, como, por exemplo, ao licenciamento ambiental (Nicolodi et al., 2018).

Outro instrumento da Política Nacional do Meio Ambiente é o Licenciamento Ambiental, o qual, segundo Milaré (2005), é um procedimento administrativo que obedece a preceitos legais, exigências e normas administrativas claramente estabelecidas, que estão cada vez mais integrados às perspectivas de empreendimentos que causam 
ou possam causar significativos impactos ao meio ambiente.

Segundo Medauar (2015), o licenciamento ambiental é um forte instrumento de apoio à implementação do Zoneamento Ecológico Econômico e, portanto, é preciso entendê-lo em um contexto mais amplo, buscando compreender suas relações entre esses instrumentos que se complementam e que têm potencial para tornar mais efetiva a proteção ambiental em território nacional.

É nesse contexto que se insere o presente trabalho, de forma a entender as relações entre

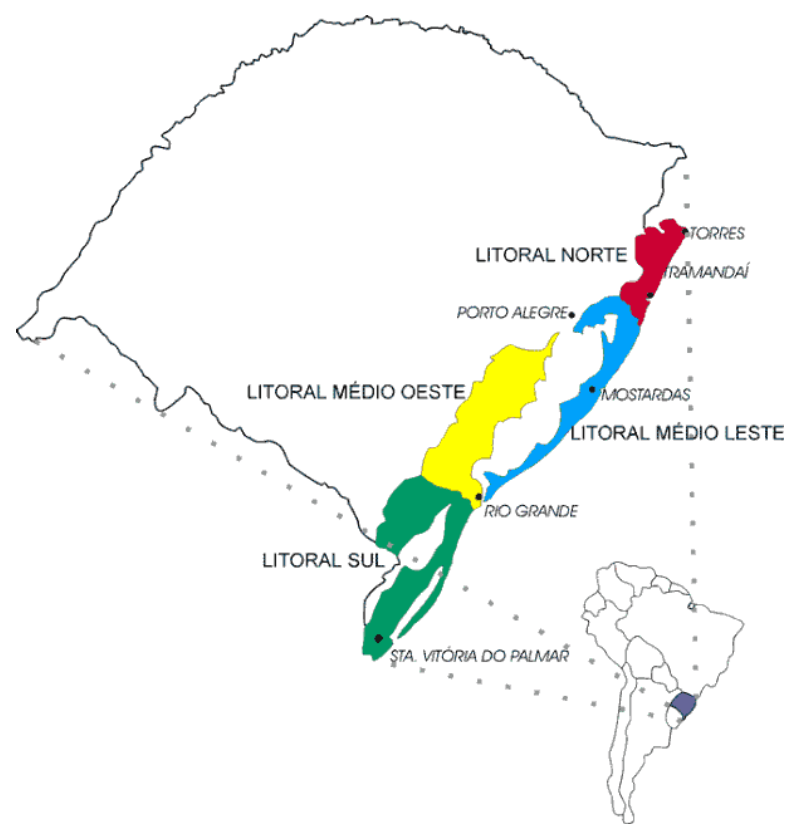

FIGURA 1 - Setorização estabelecida pelo órgão de meio ambiente estadual para fins de gestão do litoral do Rio Grande do Sul, sendo objeto do presente estudo o litoral norte (em vermelho).

FONTE: FEPAM (2000). esses dois importantes instrumentos para a gestão da zona costeira do RS: o ZEEC e o licenciamento ambiental. Para tanto, foi utilizada a atividade de extração mineral de areia e seu processo de gestão associado no litoral norte do RS. Cabe destacar que o litoral do RS está divido em três setores: litoral norte, litoral médio e litoral sul, conforme Figura 1. Já a Figura 2 mostra em detalhes os municípios que compõem essa compartimentação do litoral norte.

Para tanto, este trabalho tem como objetivo avaliar a utilização do Zoneamento Ecológico-Econômico Costeiro do RS como ferramenta de

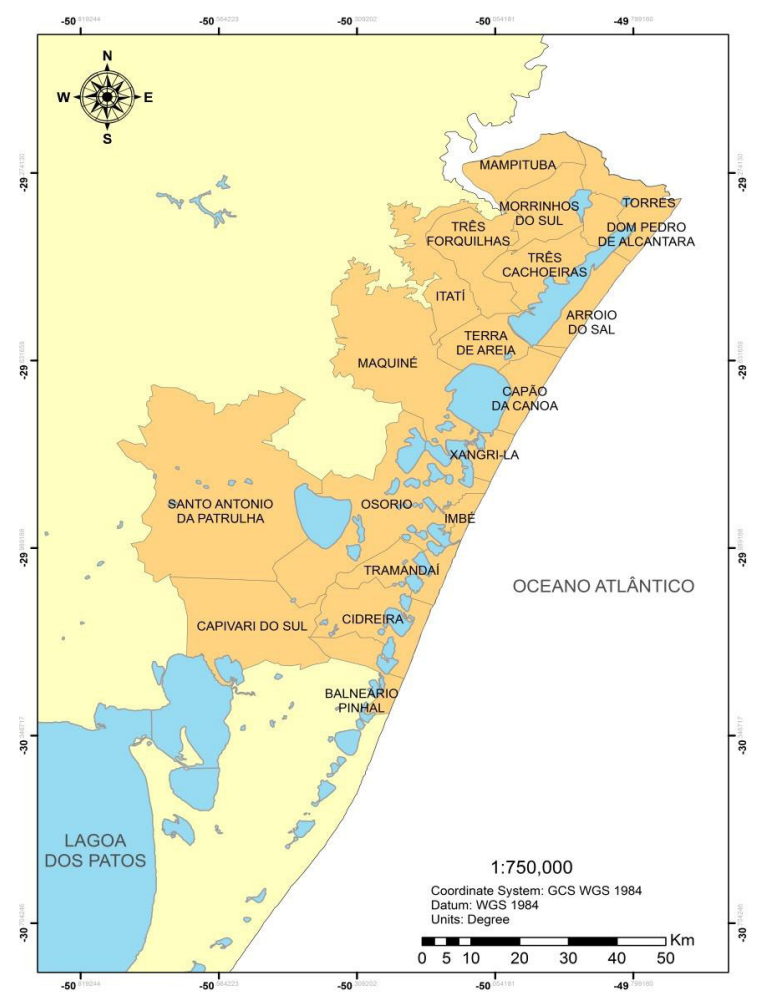

FIGURA 2 - Municípios que compõem o litoral norte do Rio Grande do Sul.

FONTE: os autores 
subsídio ao licenciamento ambiental da atividade de extração mineral de areia, tendo como base o processo de gestão denominado "Adequação das Atividades de mineração de areia às Diretrizes do Zoneamento Ecológico-Econômico no litoral norte do Rio Grande do Sul" (Haase et al., 2003).

Busca-se aqui verificar se os processos de licenciamento ambiental referentes à atividade de extração mineral de areia fazem referência ao Zoneamento Ecológico Econômico do litoral norte (ZEEC) e se tais referências estão de acordo com as diretrizes do instrumento. Além disso, foi analisada a situação atual das mineradoras após o término do processo de adequação das atividades de extração mineral de areia às diretrizes do ZEEC, tendo como base o ajuste delas às Diretrizes do Zoneamento Ecológico-Econômico no litoral norte do Rio Grande do Sul.

\section{Métodos}

A execução do presente trabalho deu-se a partir de duas fases, descritas a seguir:

\subsection{Fase 1: análise da tipologia extração mineral}

O primeiro passo foi a identificação de atores sociais responsáveis pela elaboração e execução do ZEEC e licenciamento ambiental no órgão ambiental estadual, com competência técnica acerca dos temas estudados. Após a identificação desses atores foi agendada uma reunião na Fepam com objetivo de verificar o interesse da instituição no tema de pesquisa, bem como solicitar o acesso às informações. Confirmada a anuência da pesquisa, foi disponibilizado um banco de dados referente às licenças ambientais do litoral norte, onde encontram-se 772 processos de requerimentos de licenças ambientais e autorizações referentes aos municípios do litoral norte no período de 2000 a 2015, classificados em ordem alfabética por municípios, constando algumas características dos empreendimentos como: tipologia, porte, potencial poluidor, coordenadas geográficas, bem como tipo e situação do processo e documentos afins.

Tendo como base essas informações, foi efetuada a padronização e sistematização dos dados aplicando-se três filtros iniciais, os quais classificaram os processos por municípios, tipologia (características) e potencial poluidor do empreendimento ${ }^{2}$. Após a aplicação do filtro, classificação e quantificação das licenças ambientais requeridas na instituição no período estudado, foi definida como amostra desta pesquisa a tipologia 'extração mineral'.

Após a definição da amostra foi realizada a análise dos processos de licenciamento junto à Fepam. Essa análise ocorreu a partir da consulta on-line dos respectivos documentos de licença no "Portal do Licenciamento Ambiental" na página eletrônica da Fepam, em que foi possível consultar a situação do processo usando o próprio número, CNPJ ou CPF, nome do empreendedor, entre outras informações. Na página da instituição foram consultados todos os processos de requerimento de licenças da atividade de extração mineral, inclusive aqueles que não apresentavam as coordenadas

\footnotetext{
${ }^{2}$ A metodologia de definição de potencial poluidor dos empreendimentos pode ser observada em https://www.fee.rs.gov.br/wp-content/uploads/2014/02/20140514metodologia_pp_2012.pdf.
} 
geográficas, estando disponíveis para consulta 27 documentos de licenças, incluídas as autorizações ${ }^{3}$. Os demais documentos que não foram encontrados foram solicitados diretamente à instituição e inseridos na pesquisa após consulta em arquivos digitais e/ou físicos.

Posteriormente à análise dos documentos de licença, foi imprescindível verificar a localização de todos os empreendimentos da amostragem. A localização dos empreendimentos ocorreu por meio da inserção das suas coordenadas geográficas em um Sistema de Informações Geográficas (SIG). Esse dado é solicitado ao empreendedor no formulário específico da atividade (requerimento para abertura de processo administrativo) e foi fundamental para identificar em qual das 14 zonas propostas no ZEEC os empreendimentos estão inseridos. Essa espacialização foi realizada a partir da sobreposição do mapa do ZEEC com as coordenadas existentes nos documentos de licença e banco de dados, o que originou um mapa com a localização exata desses empreendimentos e suas respectivas zonas.

Simultaneamente à análise do mapa, foi executada uma análise detalhada do Caderno da Fepam "Diretrizes Ambientais para o Desenvolvimento dos Municípios do litoral norte do RS" (FEPAM, 2000), identificando as características de cada zona, metas, potencialidades e restrições quanto à atividade de mineração. Diante dessas duas ferramentas foi possível analisar se cada deferimento ou indeferimento de licença estavam de acordo ou desacordo com as diretrizes da zona onde o empreendimento estava localizado, e se no documento era feita alguma refe- rência ao ZEEC e suas diretrizes nas suas avaliações (condições e restrições).

\subsection{Fase 2: análise do processo de adequação das mineradoras do litoral norte do $R S$}

A segunda fase desta pesquisa parte da discussão sobre determinados pontos específicos acerca das licenças ambientais em desacordo com as diretrizes do ZEEC emitidas, a qual demanda uma análise mais aprofundada do processo de negociação realizado entre a instituição e os diversos atores envolvidos no processo de adequação da atividade de extração mineral de areia do litoral norte do RS às diretrizes do ZEEC.

$O$ ponto de partida desta segunda fase da pesquisa foi a leitura crítica do "Plano de Ação para Adequação das Atividades de Mineração de Areia às Diretrizes do Zoneamento Ecológico-Econômico no Litoral Norte do Rio Grande do Sul" (FEPAM, 2002) e os documentos gerados nas suas duas etapas: diagnóstico da situação das mineradoras de areia no litoral norte e processo de negociação do conflito. Tal leitura possibilitou uma visão geral de todo o processo de gestão realizado pela instituição e forneceu as diretrizes para os resultados finais do trabalho.

Primeiramente a análise foi realizada nos dois documentos gerados na fase do diagnóstico: o trabalho intitulado "Matriz Econômica do Litoral Norte do $R S$ " (Accurso, 2002) permitiu compreender o contexto econômico do litoral norte, possibilitando,

\footnotetext{
${ }^{3}$ A Autorização Ambiental aprova a localização e autoriza a instalação, operação e/ou implementação de atividade que possa acarretar alterações ao meio ambiente, por curto e certo espaço de tempo, de caráter temporário ou a execução de obras que não caracterizem instalações permanentes, de acordo com as especificações constantes dos requerimentos, cadastros, planos, programas e/ou projetos aprovados, incluindo as medidas de controle ambientais e demais condicionantes determinadas pelo IAP (SEMA, 2015, Art. 6).
} 
assim, delimitar a importância relativa de suas atividades e principalmente da atividade de mineração de areia na região.

O banco de dados utilizado na segunda fase desta pesquisa é oriundo do diagnóstico "Caracterização e sistematização das informações referentes às atividades de extração de areia no litoral norte do $R S^{\prime \prime}$ (Ulmann, 2002). Foram realizadas análise e sistematização de duas informações principais: "Minas de areia registrada no litoral norte do RS", a qual apresenta os dados das minas de areia registradas, município, sua situação (ativa e inativa) e "Frentes de lavra de areia licenciadas pela Fepam em desacordo com o ZEE no litoral norte", a qual classifica a mina de acordo com o tipo de lavra, município e validade da licença, como também identifica em quais zonas as mineradoras estão localizadas e sua compatibilidade com o ZEEC. Além dessas informações, foram utilizadas as fichas de cadastro das 35 minas de areia que compõem o banco de dados da Fepam.

Após a sistematização dos dados sobre os empreendimentos de extração de areia no litoral norte do RS, foram analisados os Termos de Compromisso Ambiental (TCA) assinados entre a Fepam e os respectivos empreendedores. Nessa análise buscou-

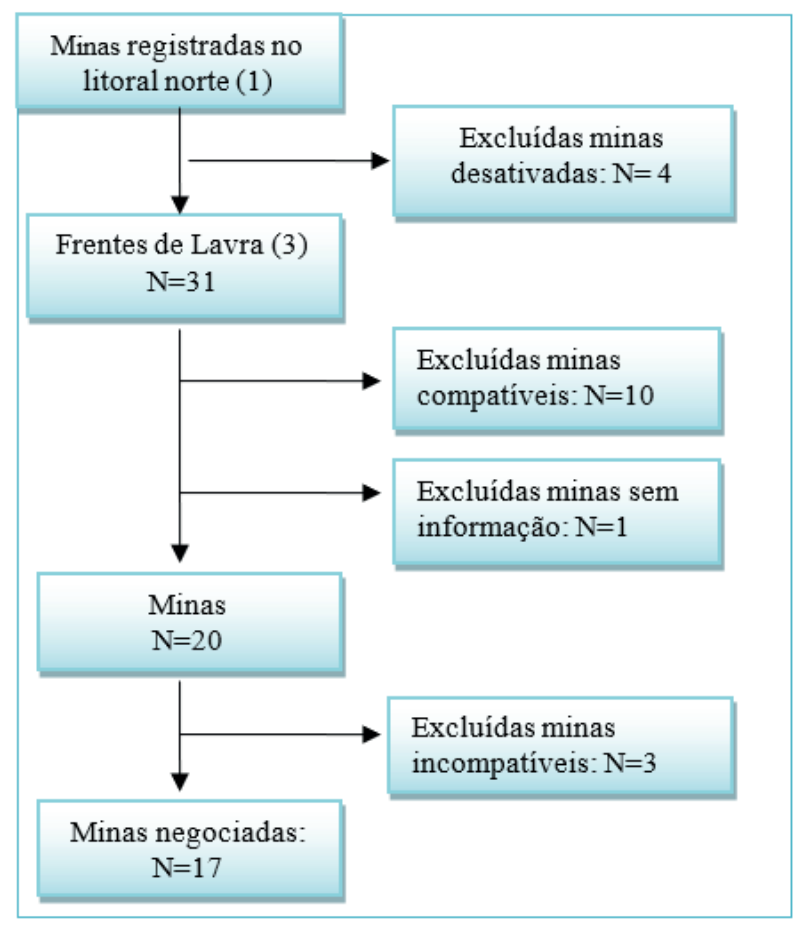

FIGURA 3 - Fluxo do processo de análise das minas de areia registradas oficialmente no banco de dados da Fundação Estadual de Proteção Ambiental (FEPAM) no litoral norte do Rio Grande do Sul.

FONTE: os autores. 
-se identificar o prazo máximo de desativação das frentes de lavra e as exigências para recuperação dos passivos ambientais das mineradoras localizadas em zonas com restrições e/ou proibições às atividades de extração mineral de areia.

Por fim, a última etapa desta fase e do trabalho foi a realização de uma verificação da situação atual das mineradoras após a assinatura do TCA, a qual consiste no acompanhamento dessas mineradoras após resultados dos estudos realizados pela Fepam e a situação atual dessas empresas após o processo de negociação e assinatura do TCA. O fluxograma da Figura 3 ilustra a metodologia descrita acima.

\section{Resultados e discussão}

A amostra referente à atividade de extração mineral no litoral norte do RS é composta por 35 processos distribuídos em 34 requerimentos de licença ambiental (Licença Prévia, Licença de Instalação e Licença de Operação) e um requerimento de Autorização. Caracterizam-se por empreendimentos de mínimo, pequeno e médio porte e com médio e alto potencial poluidor. Estão classificadas em seis tipos: extração de água mineral subterrânea, extração de argila, extração de basalto, extração de rocha para construção civil, extração de saibro, britagem e extração de areia.

Após a aplicação do filtro, classificação da amostra e quantificação das licenças, os processos de licenciamento ambiental da mineração foram classificados em quatro categorias, a saber: licenças deferidas, licenças indeferidas, autorizações deferidas e autorizações indeferidas, como são mostradas na Tabela 1.

A análise dos documentos de licença e autorização consultados na página eletrônica da Fepam permitiu verificar se o ZEEC é considerado na análise de uma licença ambiental para o empreendimento de mineração e, ainda, se nesse havia alguma referência explícita ou implícita ao instrumento. A partir dessa análise pôde-se constatar que, dos 35 documentos investigados, o ZEEC foi citado em apenas nove e não citado em 26 licenças, como mostra a Tabela 2.

Como mostrado na Tabela 2, o ZEEC não foi citado em 26 dos 35 documentos (74\%) analisados e citado em apenas nove deles (26\%). Ainda assim, infere-se que o instrumento é utilizado como uma con-

TABELA 1 - Processos da Tipologia Extração Mineral no litoral norte do Rio Grande do Sul.

\begin{tabular}{lccc}
\hline \multicolumn{1}{c}{ Descrição } & Deferidas & Indeferidas & Total \\
\hline Licenças & 23 & 11 & 34 \\
& 0 & 1 & 1 \\
Autorizações & 23 & 12 & 35 \\
\hline Total & & & \\
\hline
\end{tabular}

FONTE: os autores.

TABELA 2 - Relação de citações existentes no Zoneamento Ecológico Econômico (ZEEC) do litoral norte do Rio Grande do Sul nas licenças ambientais emitidas pela Fepam para atividade de extração mineral de areia.

\begin{tabular}{lccc}
\hline Descrição & $\begin{array}{c}\text { ZEEC citado } \\
\text { no Lic. } \\
\text { ambiental }\end{array}$ & $\begin{array}{c}\text { ZEEC não } \\
\text { citado } \\
\text { no Lic ambiental }\end{array}$ & Total \\
\hline Deferimentos & 1 & 22 & 23 \\
Indeferimentos & 8 & 4 & 12 \\
\hline Total & 9 & 26 & 35 \\
\hline
\end{tabular}

FONTE: os autores. 
dicionante técnica que pode viabilizar ou inviabilizar uma licença ambiental. Destaca-se o papel relevante do ZEEC quando dos indeferimentos impetrados pela Fepam, sendo o instrumento aplicado majoritariamente como um critério de restrição à licença ambiental.

Para a continuação da análise foi fundamental verificar a localização dos empreendimentos pesquisados. Como em 26 dos 35 documentos de licença não havia nenhuma referência ao ZEEC, a espacialização dos processos de licenciamento permitiu identificar em quais das 14 zonas do ZEEC esses empreendimentos estavam inseridos, bem como confirmar as informações encontradas no banco de dados e documentos das licenças.

Por meio da inserção das coordenadas geográficas constantes no banco de dados e nos documentos de licença ambiental em ambiente SIG, foi possível avaliar a compatibilidade dos empreendimentos de mineração com as diretrizes do ZEEC. A espacialização no mapa e da relação entre as diretrizes definidas no ZEEC foram identificadas as zonas em onde os empreendimentos estavam localizados e se essas áreas permitem, proíbem ou restringem a atividade de mineração (Figura 4).

Segundo as diretrizes ambientais do ZEEC, as zonas onde há potencialidade da atividade de mineração são: Zona 3- Campos (acima do lençol freático), Zona 4- Áreas úmidas novas, Zona 5- Vales e Zona 12-Coxilhas das Lombas. As zonas onde a atividade não é permitida são: Zona 1- Dunas, Zona 3- Campos (abaixo do lençol freático), Zona 6- Lagoas, e Zona 8- Banhados.

AZona 3 (Campos), é caracterizada como uma área de restrição de usos onde a extração mineral é permitida, porém somente possível acima do lençol freático para que não ocorram modificações no seu nível natural. Segundo Haase et al. (2003), esse é um dos principais impactos ambientais que as minerações de areia têm provocado no litoral norte do RS, por ser o lençol freático muito superficial na região. As alterações na paisagem, causadas pela abertura das cavas que formam grandes lagos (tanques) abaixo do nível do lençol freático, alteram significativamente as condições hidrológicas locais (Cabrera, 2016).

As zonas identificadas com maior número de empreendimentos de mineração foram a Zona 4 (Áreas úmidas novas) e a Zona 5 (Vales), totalizando 22 empreendimentos implantados nessas duas zonas onde é permitido o desenvolvimento de atividade de mineração. Nas Zonas 1 (Dunas), 6 (Lagoas) e 8 (Banhados), as quais não se permitem essa atividade, estão implantados oito empreendimentos. Os demais empreendimentos (cinco) estão localizados na Zona 3 (Campos) e no limite entre duas zonas. A Figura 5 mostra a tipologia das áreas e número de atividades de mineração existentes em cada uma delas.

Mesmo que o ZEEC não seja referenciado em $74 \%$ dos documentos para o licenciamento ambiental, 32 requerimentos estão em conformidade com as diretrizes da zona onde esses empreendimentos estão localizados, enquanto que, apenas três licenças estão em desconformidade com as diretrizes do ZEEC.

As licenças ambientais concedidas em desconformidade com as diretrizes do ZEEC apontaram uma anomalia no processo de regularização ambiental dessas atividades e, por isso, mereceram a uma investigação mais detalhada. Um dos casos diz respeito ao indeferimento da licença ambiental em uma zona compatível com a mineração (Zona 4), estando em desacordo com as diretrizes do ZEEC. Como nesse caso o zoneamento não foi citado no 


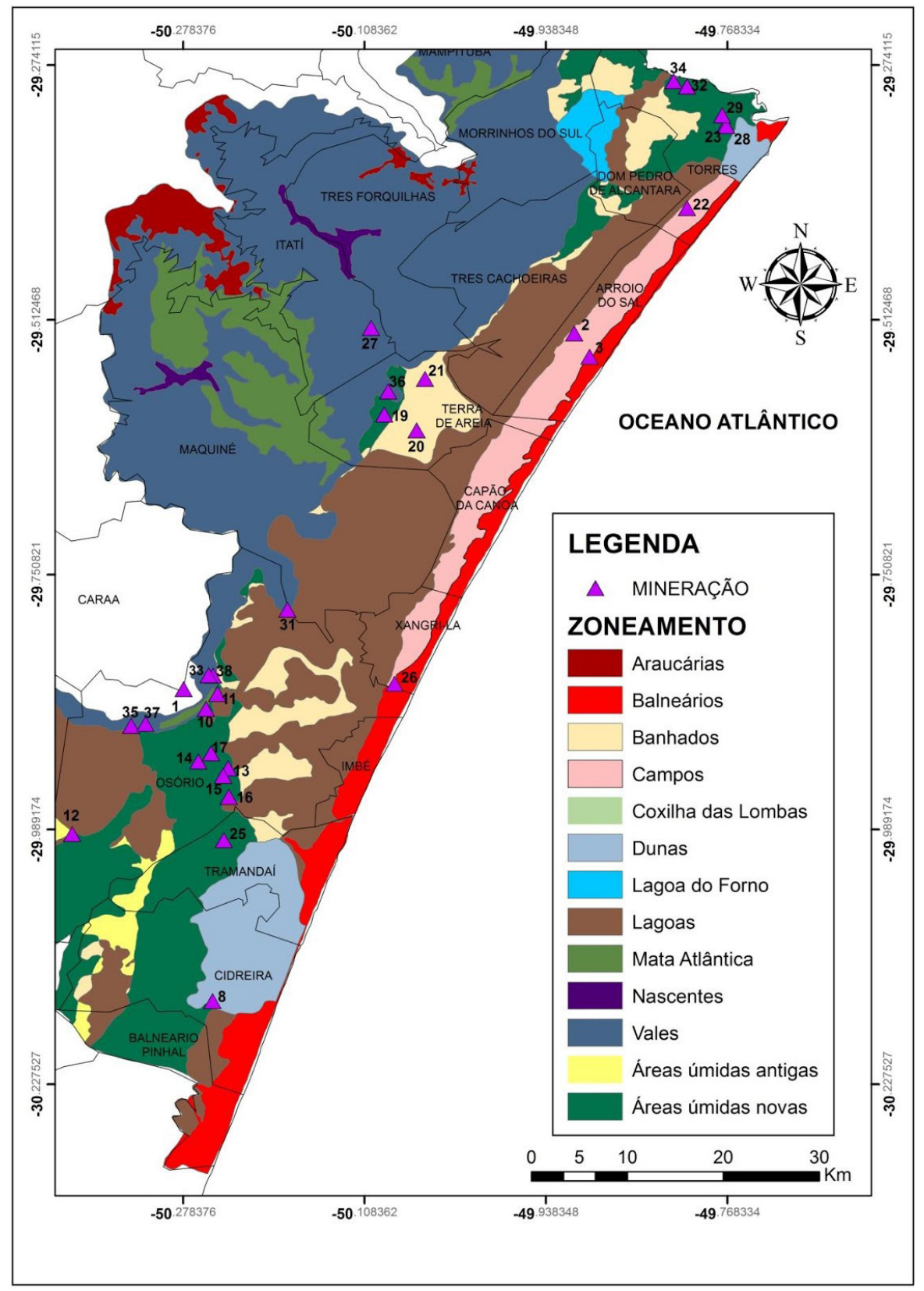

FIGURA 4 - Localização dos empreendimentos de mineração de areia em relação às zonas definidas no Zoneamento Ecológico Econômico (ZEEC) do litoral norte do Rio Grande do Sul.

FONTE: os autores 
documento, não foi possível avaliar claramente o real motivo do indeferimento. Os outros dois casos, considerados mais complexos, referem-se ao deferimento de licença ambiental (LI e LO, respectivamente) para dois empreendimentos localizados em zonas onde a atividade não é recomendada. Além dessas licenças não estarem de acordo com os requisitos de avaliação, já existiam licenças anteriores (LP e LI, respectivamente), as quais viabilizaram a atividade desses empreendimentos nessas zonas, $\mathrm{o}$ que contraria o ZEEC.

As dúvidas e questionamentos gerados na primeira fase da pesquisa motivaram uma reorientação do trabalho, a qual buscou uma melhor compreensão da importância do conflito evidenciado pela ativida- de de extração mineral de areia do litoral norte do RS durante o processo de implantação do ZEEC. Conflito esse que resultou em um processo de gestão e adequação da atividade de mineração às diretrizes do ZEEC, visto que nesse período a atividade já existia e os empreendimentos de mineração estavam licenciados pela Fepam.

A pesquisa documental realizada sobre o "Plano de Ação para Adequação das Atividades de Mineração de areia às Diretrizes do Zoneamento Ecológico-Econômico no Litoral Norte do Rio Grande do Sul", bem como nos documentos gerados nas suas duas fases (Diagnóstico da situação das mineradoras de areia no litoral norte e Processo de negociação do conflito), aponta para o fato de que

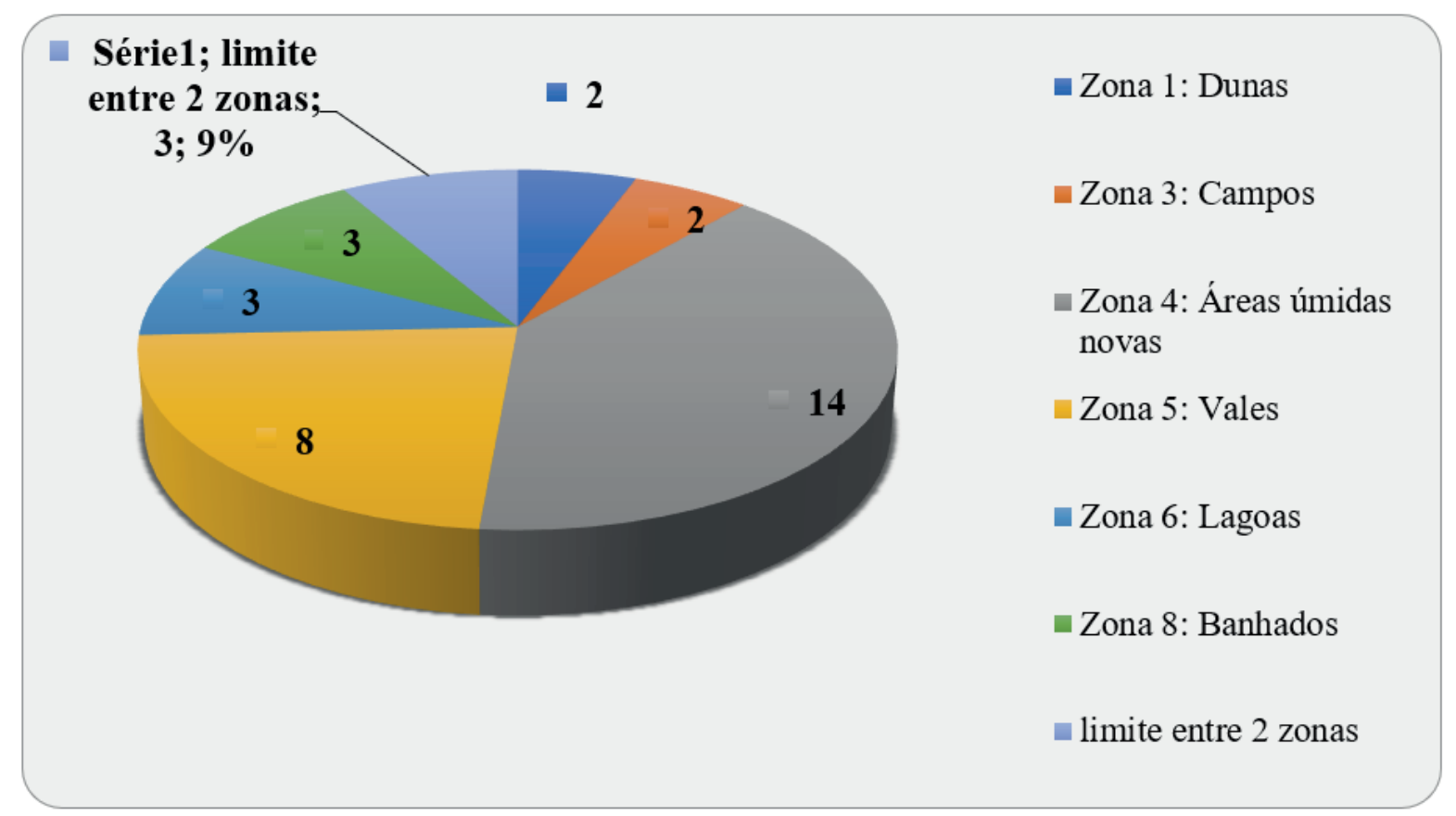

FIGURA 5 - Espacialização das atividades de extração mineral (por empreendimento) nas zonas definidas no Zoneamento Ecológico Econômico (ZEEC) do litoral norte do Rio Grande do Sul.

FONTE: os autores. 
10 extrações de areia estão localizadas em zonas compatíveis com as diretrizes do ZEEC (Zonas 4 e 12) e, portanto, não necessitam de adequação de suas atividades. Das outras 25 mineradoras, 14 estão em zonas incompatíveis (Zonas 1, 6 e 8) e seis em zonas com restrições (Zona 3). Ainda existem cinco minas localizadas em zonas parcialmente compatíveis, no limite entre duas zonas (uma permitida e uma não permitida), como mostrado na Tabela 3.

Observou-se que, das 25 atividades de mineração localizadas em zonas não permitidas, parcialmente permitidas ou com restrições, 17 passaram por um processo de adequação ou desativação gradual das minas que estavam em desconformidade com as diretrizes do ZEEC. Além das minas localizadas em zonas compatíveis com as diretrizes, foram excluídas do processo de negociação algumas minas já desativadas na época do conflito, assim como outras das quais não foi possível identificar o motivo da exclusão, por falta de informação disponível durante a pesquisa.

O plano de adequação da mineração iniciou com a elaboração dos diagnósticos referentes as 35 minas de areia registradas no litoral norte, realizados em 2002 e se consolidou com o processo de negociação do conflito, caracterizado pelas quatro etapas de reuniões e negociações com as mineradoras que estavam desconformes às diretrizes do ZEEC. Após um período de negociações, 17 mineradoras localizadas em áreas conflitantes iniciaram esse processo de adequação e/ou desativação das suas atividades. As mineradoras em estudo estão localizadas nos municípios: Arroio do Sal (duas mineradoras) Imbé (uma), Maquiné (quatro), Osório (sete), Terra de Areia (duas) e Xangri-lá (uma).

Com relação às zonas do ZEEC, 12 mineradoras estão localizadas nas zonas 3 (Campos), 6 (Lagoas) e
8 (Banhados) e cinco mineradoras estão localizadas no limite entre duas zonas, como ilustra Figura 6.

TABELA 3 - Compatibilidade dos empreendimentos de mineração de areia do litoral norte em relação às zonas definidas no Zoneamento Ecológico Econômico (ZEEC) do litoral norte do Rio Grande do Sul.

\begin{tabular}{lcc}
\hline \multicolumn{1}{c}{ Zonas ZEE } & Mineradoras & Porcentagem \\
\hline Compatíveis & 10 & $29 \%$ \\
Incompatíveis & 14 & $40 \%$ \\
$\begin{array}{l}\text { Permitida com } \\
\text { restrições }\end{array}$ & 6 & $17 \%$ \\
$\begin{array}{l}\text { Parcialmente } \\
\text { compatíveis }\end{array}$ & 5 & $14 \%$ \\
\hline Totais & 35 & $100 \%$ \\
\hline
\end{tabular}

FONTE: os autores.

O processo de negociação entre a Fepam e os atores sociais envolveu quatro etapas distintas. Foi iniciado com uma reunião entre os técnicos da Fepam em outubro de 2002, cujo objetivo foi a "Montagem de uma estratégia para desativação das minas de areia em desconformidade no litoral norte, com o ZEE". Após montada a estratégia, composta pelo cronograma de reuniões com todos os envolvidos, a Fepam iniciou os contatos com os mineradores de minas em zonas irregulares para juntos estabelecerem o cronograma e as diretrizes para desativação das frentes de lavra em desconformidade.

Esse processo de negociação encerrou-se por meio da assinatura dos Termos de Compromisso Ambiental (TCAs) entre a Fepam e respectivos empreendedores. O TCA definiu o prazo máximo de desativação das frentes de lavra e as exigências para recuperação dos passivos ambientais das mineradoras localizadas em zonas com restrições e/ ou proibidas. 
As assinaturas dos TCAs ocorreram entre 2003 e 2007. O objetivo desses termos foi estabelecer os procedimentos e prazos a serem cumpridos pelo minerador para o encerramento da atividade de lavras, os prazos de desativação das minas iniciaram em 2004 e terminariam em 2010. Nos TCAs também foram estipulados os prazos para a recuperação do passivo ambiental, período determinado para que a mina de areia possa recompor, corrigir ou minimizar os efeitos da degradação ambiental causados pela extração de areia nas zonas não permitidas. Os prazos de desativação e recuperação da área foram negociados e determinados de forma diferente para cada minerador, conforme a situação da mina encontrada na época da gestão do conflito (Figuras 7 e 8). A Fepam realizou duas vistorias técnicas em 04 de junho e 29 de dezembro de 2010, para acompanhamento e cumprimento dos TCAs. Segundo Haase et al. (2003), as mineradoras que, no curso desse processo, não cumpriram prazos de complementação de documentos, tiveram suas atividades definitivamente encerradas pela Fepam.

Das 17 mineradoras, 11 estavam em zonas totalmente incompatíveis com o ZEEC (zonas 3, 6 e 8) e o TCA determinou a desativação das atividades na respectiva área. As outras seis mineradoras estavam localizadas em zonas parcialmente incompatíveis, com a extensão da mina abrangendo mais de uma zona. Nessas o TCA determinou encerramento das atividades nas zonas impróprias, podendo haver continuação das atividades nas zonas permitidas após o cumprimento do prazo de vigência do referido termo.

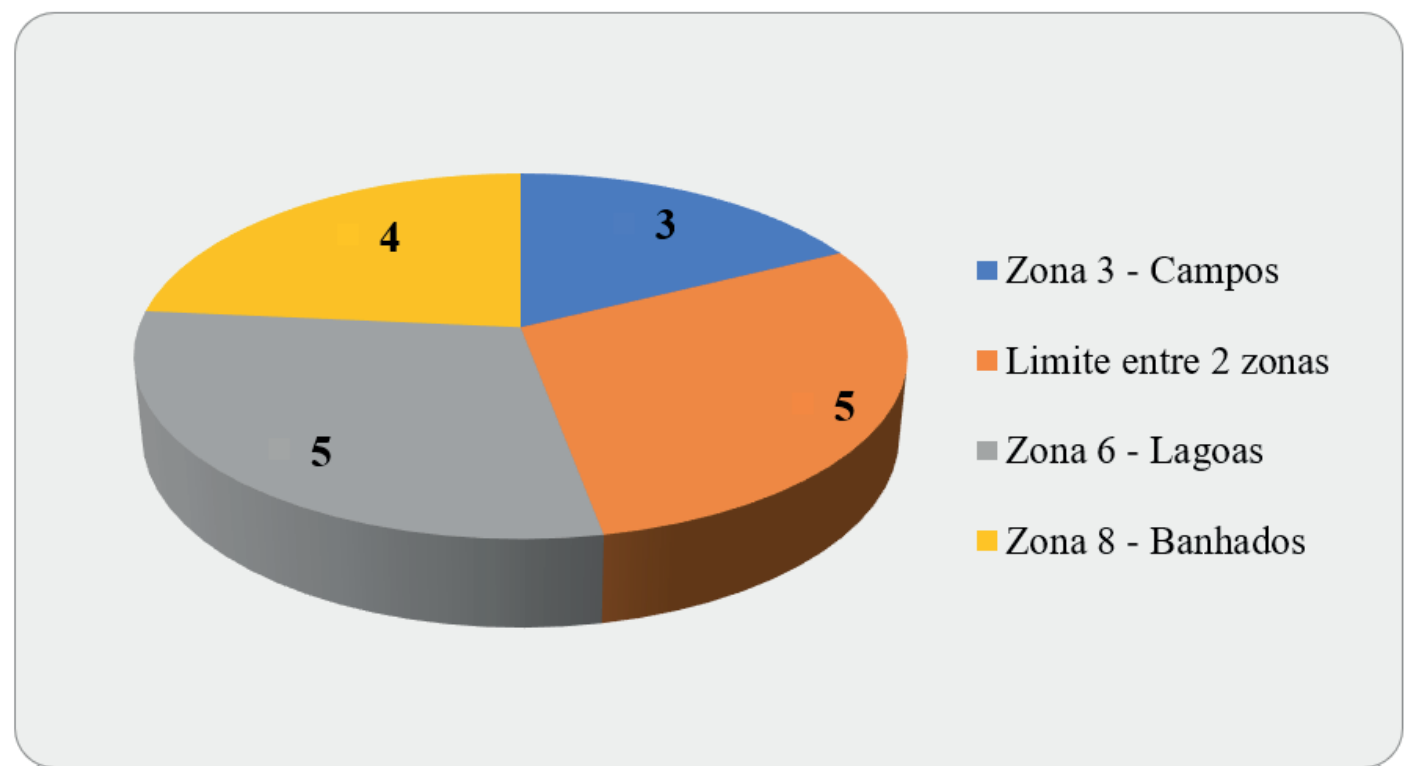

FIGURA 6 - Número de empreendimentos de mineração de areia em processo de adequação por zonas definidas no Zoneamento Ecológico Econômico (ZEEC) do litoral norte do Rio Grande do Sul.

FONTE: os autores. 
As zonas do ZEEC que são citadas no TCA referem-se às zonas da área de registro da mineradora no Departamento Nacional de Produção Mineral (DNPM). Antes da elaboração do TCA, a Fepam solicitou aos mineradores envolvidos no processo de adequação alguns documentos complementares, inclusive a planta topográfica (com amarração ou georreferenciada) da área já minerada e das frentes de lavras atuais contendo os limites da poligonal re-

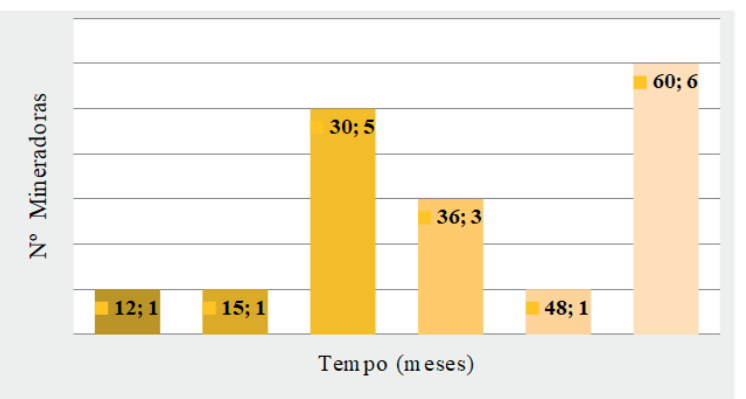

FIGURA 7 - Prazo de desativação de empreendimentos de mineração de areia do litoral norte definidas como incompatíveis com o Zoneamento Ecológico Econômico (ZEEC) do litoral norte do Rio Grande do Sul. FONTE: os autores.

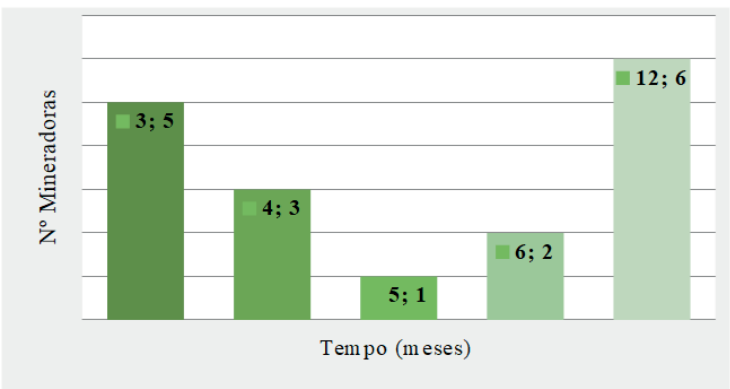

FIGURA 8 - Prazo de recuperação de área degradada de empreendimentos de mineração de areia do litoral norte incompatíveis com o ZEEC.

FONTE: os autores. ferente ao seu processo no DNPM (FEPAM, Ofício circular $n^{\circ} 6773 / 2002$ ).

Com base em consulta ao banco de dados da Fepam, verificou-se a existência de licença ambiental emitida ao empreendimento posterior à assinatura do termo, fazendo-se permitido o seu funcionamento em zona onde a atividade é proibida. Além disso, buscou-se identificar o andamento dos processos dentro da instituição após a assinatura do documento, bem como esclarecer como findou o processo de adequação para cada mineradora, além de coletar informações complementares dos respectivos processos, as quais não estavam disponíveis na versão on-line do banco de dados.

A Figura 9 ilustra, respectivamente, a situação das mineradoras após a assinatura do TCA e o cumprimento das condicionantes do termo após o prazo de vigência.

Embora estivessem localizadas em zonas proibidas para extração mineral (zonas 6 e 8) e necessitando de adequação das atividades conforme as diretrizes do ZEEC, três mineradoras foram liberadas para exercerem suas atividades extrativas de areia em março de 2011 por meio de um documento firmado entre Secretaria Estadual do Meio Ambiente do RS (Sema), Fepam e as empresas citadas. Segundo o Jornal Revisão (2011), essas empresas contrataram uma equipe transdisciplinar que realizou estudos técnicos nas áreas relacionadas ao meio ambiente que comprovaram a viabilidade das atividades.

Os trabalhos realizados ao longo de 18 meses conseguiram demonstrar ao órgão de proteção ambiental que não haveria mais problemas para o meio ambiente de nossa cidade a continuidade da lavra de areia se fosse feito conjuntamente a recuperação e reparação das respectivas áreas de mineração [...] (Jornal Revisão, 2011, p. 9). 
Como citado no jornal, os trabalhos ainda recomendam a atualização do ZEEC do litoral norte, o qual originou os embargos a uma grande quantidade de empresas mineradoras da região.

Em dois dos processos analisados não foram disponibilizadas informações conclusivas sobre o cumprimento do TCA, desativação ou recuperação da área degradada, embora os processos tivessem disponíveis para consulta.

A Figura 9B ilustra a situação atual dos Termos de Compromisso Ambiental assinados pelas mineradoras, conforme verificação nos documentos on-line e nos referentes processos disponíveis para consulta na Fepam ao final desta pesquisa.

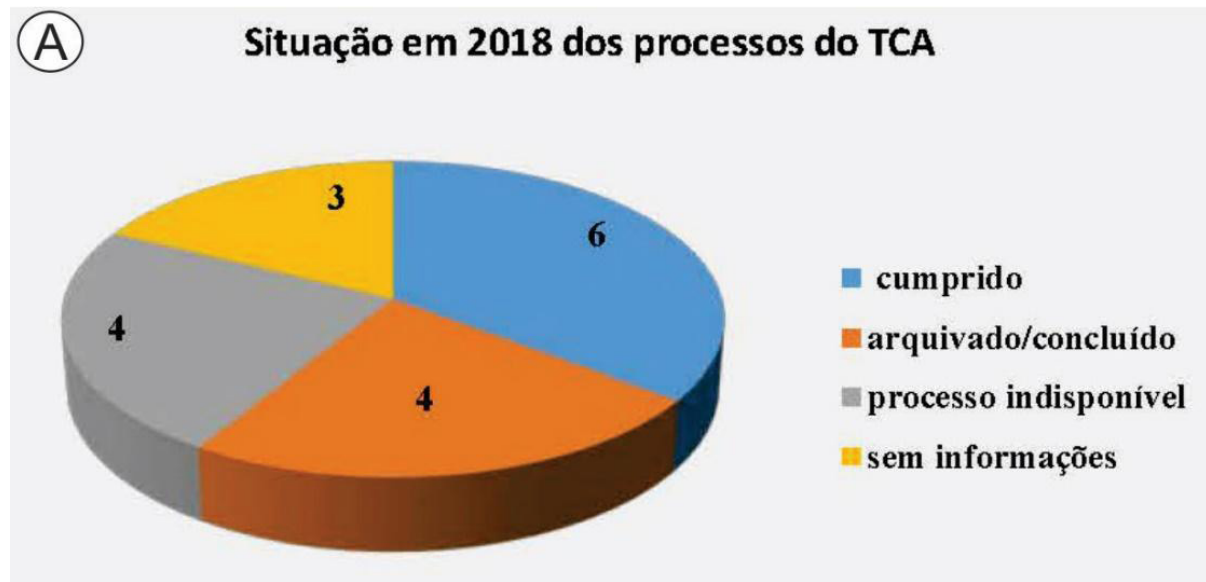

(B) Situação das mineradoras após assinatura do TCA

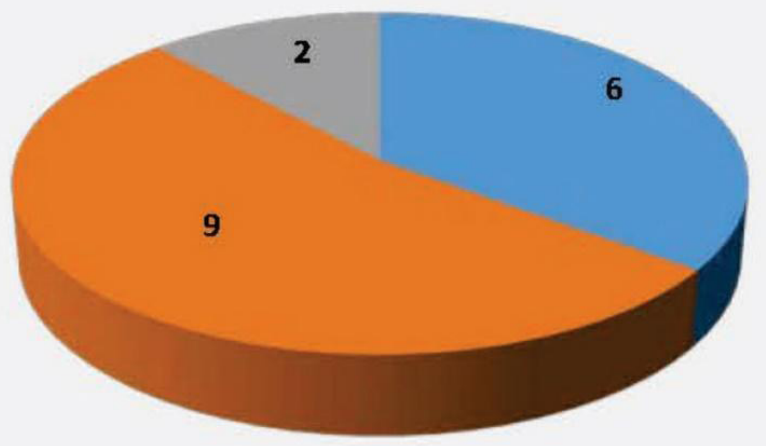

ativas

desativadas

sem informações

FIGURA 9 - (A) Situação dos processos de Termo de Compromisso Ambiental (TCA) em 2018 e (B) Situação dos empreendimentos de mineração de areia do litoral norte após assinatura do Termo de Compromisso Ambiental (TCA).

FONTE: os autores. 


\section{Considerações finais}

A presente pesquisa buscou avaliar a utilização do Zoneamento Ecológico-Econômico Costeiro do RS, instrumento de gestão do PNGC e elaborado pelo GERCO-RS, como ferramenta de subsídio ao licenciamento ambiental da atividade de extração mineral de areia no litoral norte do RS.

A partir da análise dos processos e seus respectivos documentos de licença, pode-se constatar que o ZEEC não foi citado em $74 \%$ dos documentos de licença ambiental analisados. Embora ocorra essa discrepância entre esses dois instrumentos de gestão, 94\% de seus pareceres estão de acordo com as diretrizes referentes às zonas onde esses empreendimentos estão localizados. Com isso, pode-se concluir que, mesmo o ZEEC não sendo mencionado em grande parte dos documentos, suas diretrizes foram observadas e respeitadas no processo de licenciamento ambiental. Destaca-se o papel relevante do ZEEC quando dos indeferimentos impetrados pela Fepam, sendo o instrumento aplicado majoritariamente como um critério de restrição à licença ambiental. Portanto o ZEEC é, na prática, um instrumento utilizado como uma condicionante técnica que pode viabilizar ou inviabilizar uma licença ambiental.

Durante a análise da referência do ZEEC nos documentos de licença ambiental e da compatibilidade dessas licenças com as diretrizes do instrumento, foram evidenciadas três situações de inconsistência que acabaram por direcionar a pesquisa para uma investigação mais detalhada do processo de licenciamento dessas mineradoras e uma melhor compreensão do conflito evidenciado pela atividade de extração mineral de areia do litoral norte durante o processo de implantação do ZEEC, visto que a atividade já existia e estava licenciada pela Fepam. Desse conflito resultou um processo de gestão e uma adequação dessa atividade às diretrizes do ZEEC.

Os resultados do processo de adequação das minas localizadas em zonas imcompatíveis e parcialmente imcompatíveis com as diretrizes do ZEE revelaram que $29 \%$ dessas instalações estavam em zonas compatíveis, não necessitando de adequação das suas atividades, e $71 \%$ encontravam-se em zonas incompatíveis, parcialmente compatíveis ou em zonas com restrições. No entanto apenas $49 \%$ passaram pelo processo de adequação ou desativação gradual, visto que algumas mineradoras localizadas nas zonas incompatíveis excluídas do processo já estavam desativadas, enquanto que em quatro das instalações não havia informações na documentação do processo.

Um dos fatores mais relevantes percebidos nesta pesquisa foi a grande dificuldade na coleta de informações junto às instituições. Começando pelo banco de dados da Fepam, no qual a informação básica de localização do empreendimento, dado importante para a espacialização das minas, estava incompleta ou então as coordenadas informadas na planilha eram diferentes daquelas encontradas na licença ambiental do mesmo empreendimento. Com relação às licenças ambientais referentes aos processos, estavam todas disponíveis no site da instituição, mas assim como não citavam o ZEEC, não citavam a zona do empreendimento.

Na segunda fase do trabalho, a ausência de determinadas informações dificultou o entendimento do processo de gestão em sua integralidade. Embora existissem alguns trabalhos publicados pela equipe da Fepam, algumas informações eram incompletas 
e confusas. A falta de padronização nas informações encontradas nos processos administrativos foi outra dificuldade. Cada processo foi negociado de forma diferente em razão da situação de irregularidade da mineradora na época da negociação do conflito, tendo como consequência resultados e processos heterogêneos.

Há de se ressaltar que não existe na instituição um banco de dados um documento ou publicação específica que demonstre o resultado do processo de gestão, principalmente após o período de vigência do TCA. Nem mesmo os servidores em atividade têm o exato conhecimento de como findou o processo, visto que as pessoas que participaram diretamente já não estão mais vinculadas à instituição e, sem o referido histórico institucional, não há como avaliar de forma completa a efetividade da gestão pública.

Atualmente, o estado do Rio Grande do Sul está desenvolvendo o seu zoneamento estadual (ZEE-RS), o qual abrangerá também a Zona Costeira. Espera-se que esse novo ZEE estadual considere as especificidades e diretrizes constantes no ZEEC litoral norte. O desenvolvimento desse novo instrumento é a oportunidade de formalizar e normatizar o planejamento territorial no litoral norte, uma vez ser o ZEEC um instrumento desatualizado, visto que foi implementado há 17 anos e elaborado por meio de tecnologias e conceitos diferentes dos existentes hoje. Além disso, o fato do ZEEC não ter sido institucionalizado e normatizado indubitavelmente o enfraqueceu ao longo dos anos, mesmo que os resultados aqui obtidos apontem para um uso efetivo desse em determinados processos de gestão.

Por fim, conclui-se que, apesar de o ZEEC do litoral norte não ser normatizado e obrigatório, cumpriu seu papel como ferramenta de planejamen- to e gestão, dando suporte a outros instrumentos de gestão como o licenciamento ambiental. Relevante ressaltar que o que determinou esse papel foi a implantação de um processo de adequação da atividade de mineração às diretrizes do ZEEC confirmando a importância dessa ferramenta no planejamento das atividades da região, uma vez que, a partir de um processo de negociação, os empreendimentos já licenciados pela Fepam iniciaram processo de adequação ou desativação das minas que estavam em desacordo com o ZEEC.

\section{Referências}

Ab'Saber, A. Zoneamento Ecológico e Econômico da Amazônia. Questões de escala e método. Estudos Avançados, 3(5). 1989. doi: 10.1590/S0103-40141989000100002

Accurso, J. S. Matriz Econômica do litoral norte. Fundação Estadual de Proteção Ambiental - FEPAM e Programa de Gerenciamento Costeiro - GERCO. Relatório. Porto Alegre - RS, 2002. Disponível em: http://www.fepam. rs.gov.br/programas/Matriz_Economica_LN.pdf. Acesso em: nov. 2016.

Araújo, C. P.; Gattamorta, M, A.; Silva, S. B. O Zoneamento Ecológico e Econômico enquanto instrumento de planejamento ambiental que antecede o planejamento urbano. In: Anais do XIV Encontro Nacional da ANPUR. Rio de Janeiro, Brasil, 2011.

Asmus, M. L.; Kitzmann, D.; Laydner, C.; Tagliani, C. R. A. Gestão Costeira no Brasil: Instrumentos, fragilidades e potencialidades. Gerenciamento Costeiro Integrado, 4 , 52-57, 2006.

Bastos, F. H.; Silva, E. V. O Zoneamento Ecológico e Econômico como Subsídio aos Procedimentos de Licenciamento Ambiental na Zona Costeira do Estado do Ceará. In: Anais do VI Seminário Latino Americano de Geografia Física e II Seminário Ibero Americano de Geografia Física. Coimbra, Portugal, 2010. 
Becker, B. K.; Egler, C. A. Detalhamento da Metodologia para Execução do Zoneamento Ecológico-Econômico pelos Estados da Amazônia Legal. Brasília: MMA/SAE. 1996.

Brasil. Decreto 5300 de 07 de dezembro de 2004. Regulamenta a Lei $\mathrm{n}^{\circ}$ 7.661, de 16 de maio de 1988, que institui o Plano Nacional de Gerenciamento Costeiro - PNGC, dispõe sobre regras de uso e ocupação da zona costeira e estabelece critérios de gestão da orla marítima, e dá outras providências. Brasília: DOU de 8/12/2004.

Cabrera, M. C. M. Valoração do impacto ambiental de cavas de mineração de areia e argila com base na evapotranspiração. São Paulo. Tese de Doutorado. Universidade de São Paulo. 2016.

Cicin-Sain, B.; Knecht, R. Integrated Coastal and Ocean Management: concepts and practices. Island Press, Washington, D.C. 1998.

FEPAM - Fundação Estadual de Proteção Ambiental. Diretrizes Ambientais para o Desenvolvimento dos Municípios do litoral norte: Zoneamento Ecológico-Econômico e Proposta de Enquadramento dos Recursos Hídricos. Cadernos de Planejamento e Gestão Ambiental, N. ${ }^{\circ} 1,2000$. Disponível em: www.fepam.rs.gov.br/programas/zee/. Acesso em: ago. 2017.

FEPAM - Fundação Estadual de Proteção Ambiental. Plano de Ação para Adequação das atividades de Mineração de areia às diretrizes do Zoneamento Ecológico-Econômico no litoral norte do Rio Grande do Sul. Programa Nacional do Meio Ambiente - PNMA II. Projeto de Fortalecimento do Gerenciamento Costeiro no litoral norte do Rio Grande do Sul, 2002.

Ferreira, V. J. R. P. Avaliação do Zoneamento Ecológico e Econômico no município do Rio de Janeiro como ferramenta para a gestão territorial integrada e desenvolvimento sustentável. Rio de Janeiro, Dissertação (Mestrado em Planejamento Energético) - UFRJ, 2011.

Gandra, T. B. R. Elementos Geomorfológicos e Socioambientais como subsídios para a elaboração do Zoneamento Ecológico-Econômico Costeiro ZEEC. Rio Grande, Dissertação (Mestrado em Oceanografia Física, Química e Geológica) - FURG, 2008.

Gruber, N. L. S.; Barboza, E. G.; Nicolodi, J. L. Geografia dos Sistemas Costeiros e Oceanográficos: Subsídios para a Gestão Integrada da Zona Costeira. Gravel, 1, 81-89, 2003.

Haase, J. F.; Langner, C.; Barbosa, N. S. F.; Lima, J. M. F. Adequação das Atividades de mineração de areia às Diretrizes do Zoneamento Ecológico-Econômico no litoral norte do Rio Grande do Sul. In: Anais do II Congresso sobre Planejamento e Gestão das Zonas Costeiras dos Países de Expressão Portuguesa, IX Congresso da Associação Brasileira de Estudos do Quaternário. Recife, 2003.

Leite, C. M. C. O. Zoneamento Ecológico e Econômico: impasses e perspectivas de um instrumento de gestão ambiental. Brasília, Dissertação (Mestrado em Geografia) - UNB, 2001.

Lima, A. Zoneamento Ecológico-Econômico: à luz dos direitos socioambientais. Curitiba, Juruá Editora, 2006. Disponível em: http://bdjur.stj.jus.br/dspace/handle/2011/2896.

Milaré, E. Direito do Ambiente: Doutrina, Jurisprudência, Glossário. $4^{\mathrm{a}}$ edição revista, ampliada e atualizada. São Paulo, Editora Revista dos Tribunais, 2005

MMA - Ministério do Meio Ambiente. Resolução CIRM $N^{o}$ 01 de 21 de novembro de 1990. Aprova o Plano Nacional de Gerenciamento Costeiro. Disponível em: <www.mma. gov.br/estruturas/sqa_sigercom/_arquivos/pngc2_78.pdf.>

Medauar, O. Coletânea de Legislação Ambiental. Constituição Federal. Revista dos Tribunais. 14 ed., 2015.

Montaño, M.; Oliveira, I. S. D.; Ranieri, V. E. L.; Fontes, A. T.; Souza, N. T. O zoneamento ambiental e sua importância para a localização de atividades. Revista Pesquisa e Desenvolvimento Engenharia de Produção, 6, 49-64, 2007.

Moraes, A. C. R. Contribuições para a Gestão da Zona Costeira do Brasil: Elementos para uma Geografia do Litoral Brasileiro. 285p. Hucitec/Edusp, São Paulo, SP, Brasil. 1999.

Nicolodi, J. L.; Asmus, M. L.; Turra, A.; Pollete, M. Avaliação dos Zoneamentos Ecológico-Econômicos Costeiros (ZEEC) do Brasil: proposta metodológica. Desenvolvimento e Meio Ambiente, 44, 378-404, 2018.

Ogata, M. G. Environmental Economic Zoning: Na ins- 
trument for regulating territory in Brazil. Business and Management Review, SI, 4(7), 2015.

Oliveira, I. S. D. A contribuição do zoneamento ecológico econômico na avaliação de impacto ambiental: bases e propostas conceituais. São Carlos. Dissertação (Mestrado em Ciências da Engenharia Ambiental) - USP, 2004.

Portz. L.; Manzolli R. P.; Corrêa I. C. S. Ferramentas de Gestão Ambiental Aplicadas na Zona Costeira do Rio Grande do Sul, Brasil. Revista da Gestão Costeira Integrada, 11(4), 459-470, 2011. Disponível em: http//www.aprh.pt/ rgci/pdf/rgci-278_Portz.pdf.

Ranieri, V. E. L. Discussão das Potencialidades e Restrições do Meio como subsídios para o Zoneamento Ambiental: o caso do Município de Descalvado (SP). Dissertação (Mestrado em Engenharia) - USP, 2000.

Santos, M. R. R. Critérios para Análise do Zoneamento Ambiental como Instrumento de Planejamento e Ordenamento Territorial. Dissertação (Mestrado em Engenharia Ambiental) - USP, 2010.

SEMA - Secretaria do Meio Ambiente e Recursos Hídricos do Paraná. Resolução $n^{\circ} 046$ de 17 de junho de 2015. Estabelece requisitos, definições, critérios, diretrizes e procedimentos administrativos referentes ao Licenciamento Ambiental e Regularização Ambiental de empreendimentos viários terrestres, públicos e privados, a serem cumpridos no território do Estado do Paraná: DOE de 03/07/2015.

Schubart, H. O. R. Zoneamento Ecológico-Econômico e a Gestão dos Recursos Hídricos. In: Muñoz, H. R. (Org.). Interfaces da Gestão de Recursos Hídricos: desafios da lei de águas de 1997. Brasília, Secretaria de Recursos Hídricos. p.155-175, 2000.

Ulmann, L. V. Caracterização e Sistematização das Informações referentes às atividades de Extração de areia no litoral norte do RS. Fundação Estadual de Proteção Ambiental - FEPAM e Programa de Gerenciamento Costeiro - GERCO. Relatório. Porto Alegre / RS, 2002.

Vasconcelos, V. V.; Hadad, R. M.; Martins Junior, P. P. Zoneamento ecológico-econômico: Objetivos e Estratégias de Política Ambiental. Gaia Scientia, 7(1), 119-132, 2013.

Zamboni, A.; Nicolodi, J. L. Macrodiagnóstico da Zona Costeira e Marinha do Brasil. 242 p. Ministério do Meio Ambiente - Instituto Brasileiro do Meio Ambiente e dos Recursos Naturais Renováveis, Brasília, DF, Brasil. 2008. 